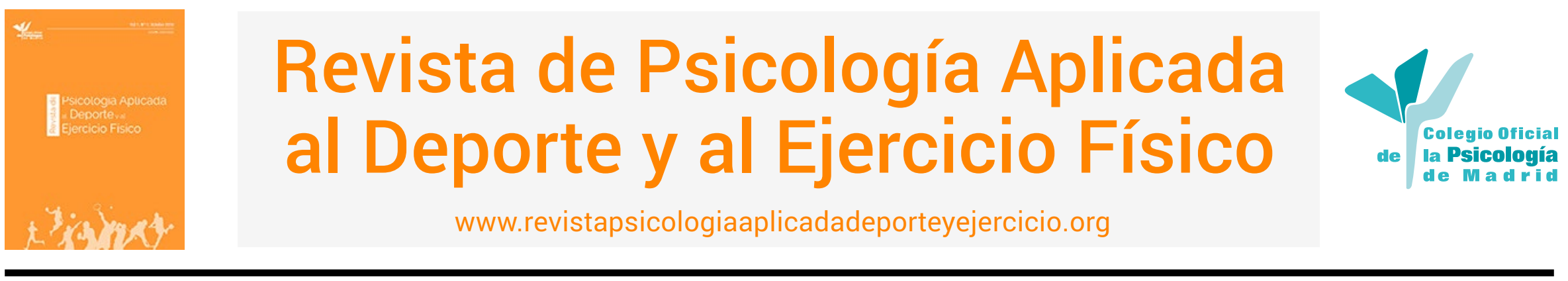

\title{
Diez ideas potenciadoras para rendir al máximo en el deporte
}

\section{David Peris-Delcampo \\ Universitat de València}

RESUMEN: El objetivo principal del presente trabajo es el planteamiento de una propuesta práctica de ideas potenciadoras en el deporte. Parte de la base de la Psicología Cognitiva que plantea que existe una interpretación de los acontecimientos que influyen en las emociones y la conducta, y la Psicología Positiva que se centra en lo que se pretende conseguir en lugar de modificar aquello que funciona mal. Se toma como base las teorías cognitivas clásicas y más significativas, junto con diversas estrategias cognitivo-conductuales para aplicar conjuntamente a la implementación de estas ideas en el entorno deportivo. Este tipo de herramientas aplicadas son cada vez más necesarias para profesionales de la psicología del deporte en busca de la optimización del trabajo psicológico en un entorno cada vez más exigente.

PALABRAS CLAVES: ideas potenciadoras, deporte, psicología cognitiva.

\section{Ten empowering ideas to perform at your best in sport}

ABSTRACT: The main objective of this work is to offer a practical proposal of empowering ideas in sport. Part of the basis of Cognitive Psychology holds that there is an interpretation of events that influences emotions and behavior, while Positive Psychology focuses on what we intend to achieve instead of on modifying what works badly. The classical and most significant cognitive theories are taken as a basis, along with various cognitive-behavioral strategies, to be jointly applied to the implementation of these ideas in the sports environment. Applied tools of this kind are increasingly necessary for sports psychology professionals in search of the optimization of psychological work in an increasingly demanding environment.

KEYWORDS: empowering ideas, sport, cognitive psychology.

\section{Dez ideias estimulantes para ter o melhor desempenho no desporto}

RESUMO: O objetivo principal deste trabalho é a apresentação de uma proposta prática de ideias estimulantes no desporto. Parte do princípio da Psicologia Cognitiva, que afirma que há uma interpretação dos acontecimentos que influenciam as emoções e o comportamento, e da Psicologia Positiva, que se concentra no que se pretende alcançar em vez de modificar o que funciona mal. Baseia-se nas teorias cognitivas clássicas e mais significativas, e ainda nas várias estratégias cognitivo-comportamentais aplicadas em conjunto de forma a implementar essas ideias no ambiente desportivo. Este tipo de ferramentas aplicadas são cada vez mais necessárias para os profissionais da psicologia do desporto a fim de otimizar o trabalho psicológico num ambiente cada vez mais exigente.

PALAVRAS-CHAVE: ideias estimulantes, desporto, psicologia cognitiva.

Artículo recibido: 20/09/2020 | Artículo aceptado: 16/11/2020

David Peris Delcampo es psicólogo. Experto en psicología del deporte (COP) y Vicepresidente de la Federación Española de Psicología del Deporte y Profesor de la Universidad de Valencia. 
Los métodos de entrenamiento deportivo han evolucionado mucho en los últimos años (Camacho et al., 2019). En relación al entrenamiento psicológico, la evolución también ha tenido que adaptarse a las demandas del deporte (e.g., mejora del rendimiento), que exige una formación especializada por parte del psicólogo/a (Cantón, 2016), para que pueda aportar soluciones eficaces, aplicando la ciencia de la Psicología, de manera óptima y adaptada al contexto deportivo (Garcia-Naveira, 2018). En este sentido, es cada vez más necesario que los y las psicólogos/as del deporte desarrollen una serie de competencias profesionales (e.g., evaluación e intervención) que les capacite para hacer bien su trabajo y que además, dispongan de una serie de herramientas (e.g., trabajo con creencias) para mejorar su desempeño (Peris-Delcampo y Cantón, 2018).

La Psicología Cognitiva es la rama de la Psicología que se centra en el estudio de la cognición, es decir de los procesos mentales implicados en el conocimiento como son la percepción, la memoria, planificación, extracción de inferencias, la toma de decisiones, aprendizaje, formación de conceptos, el razonamiento lógico, etc. (García y Rajo, 2020).

Desde los años '50 hasta la actualidad, se ha desarrollado esta disciplina que se basa en el procesamiento de la información, con el supuesto de que son los pensamientos, ideas, imágenes... las que actúan de filtro cognitivo que determina nuestras emociones y nuestras actuaciones (Eysenk, 1990). A modo de ejemplo gráfico, un esquema generalmente utilizado para entender esta cuestión es el de Wright (1988), en el que se observa que cuando ocurre un acontecimiento (situación), se produce una valoración cognitiva (ese "filtro" en forma de pensamientos automáticos, imágenes, ideas preconcebidas...) y en función de eso aparece la emoción y

Figura 1. Esquema del procesamiento cognitivo de la información. Adaptado de Wright (1988).

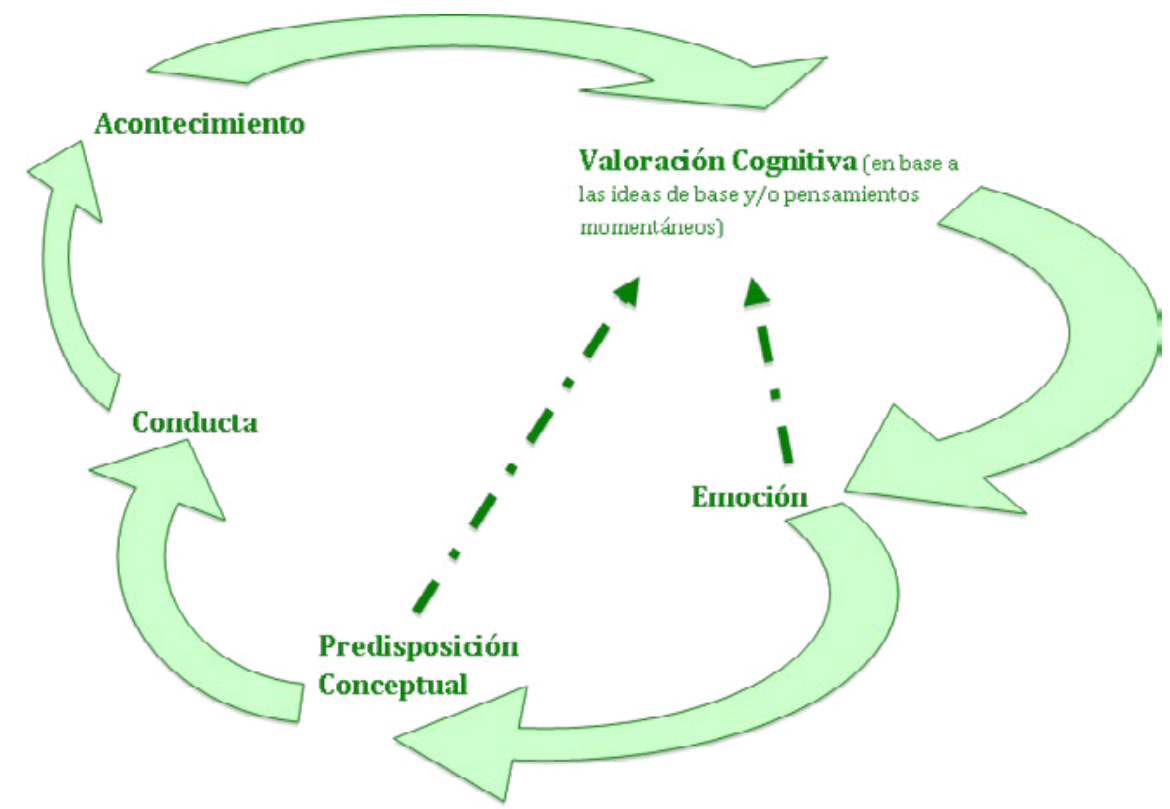

la predisposición conceptual en base a todo lo anterior y de los esquemas mentales previos del individuo, para después producirse la conducta, que a su vez influye en el siguiente acontecimiento y así se repite el ciclo, donde cada una de las partes influye en la otra según se observa en el esquema de la Figura 1.

Desde sus inicios, han ido surgiendo distintas propuestas clásicas (evolucionadas a lo largo de los años), relacionadas con la Psicología Cognitiva, como la Terapia Cognitiva de Aaron Beck, basada en la detección de distorsiones cognitivas o errores de pensamiento para después modificarlas (Beck, 1987; Beck, 1995), o la Terapia Racional Emotiva de Albert Ellis, en la que identifica una serie de ideas o creencias irracionales para después confrontarlas con la realidad y modificar el pensamiento (Ellis, 1980).

También aparecieron otras propuestas como la Teoría de la Disonancia Cognitiva (Festinger, 1975), la Teoría sobre la Zona de Desarrollo Próximo (Vygotsky, 1979), Estrés y Procesos Cognitivos (Lazarus y Folkman, 1986) o algunas más recientes como la Teoría de los Marcos Relacionales y su evolución hacia la Terapia de Aceptación y Compromiso (Hayes et al., 2015) o la Terapia Cognitiva basada en el Mildfuldness (Segan et al., 2015), por poner algunos ejemplos relevantes.

Con la creciente evolución de la Psicología Positiva, surgen planteamientos relacionados con incorporar aquellos recursos, estrategias, acciones... que facilitan el buen funcionamiento de las personas, en lugar centrarse en un enfoque más clásico que pretende detectar aquello que funciona mal para después cambiarlo (The APA 1998 Annual Report, 1999).

En el deporte, existen diferentes trabajos relacionados con la Psicología Cognitiva aplicada (Del Valle y De la Vega, 2008), como por ejemplo Mildfulness (Palmi y Solé, 2016), personas mayores y funcionamiento cognitivo (Fernández-Campoy et al., 2016), actividad física y sus efectos cognitivos en adolescentes (Reigal et al., 2016), aspectos motores y cognitivos en preescolares (Alesi et al., 2019), procesos cognitivos en bailarines (Nieto et al., 2020), burn out (García-Jarillo et al., 2020), fatiga mental y rendimiento (Alarcón et al., 2017) o intervención a distancia en fútbol (Peris-Delcampo, 2019).

El objetivo principal del presente trabajo es el de ofrecer una herramienta práctica, relacionada con la Psicología Cognitiva junto con el reciente enfoque de la Psicología Positiva, que pretende facilitar el funcionamiento de los diferentes agentes del deporte. Se proponen diez ideas potenciadoras que facilitan el rendimiento en el deporte y algunas estrategias para poder implantarlas en el deporte (Peris-Delcampo, 2019, 2020). 


\section{El pensamiento potenciador en el deporte}

Un pensamiento potenciador, es aquél que favorece el buen funcionamiento del deportista y ayuda a que sean capaces de dar su máximo en aquello que desempeña (Peris-Delcampo, 2020). En este sentido y en base a las teorías clásicas y recientes de Psicología Cognitiva (e. g. Beck, 1987; Ellis, 1980; Hayes et al. 2015), un pensamiento potenciador es aquél que no está distorsionado ni es irracional, es decir, se basa en afrontar la realidad tal y como es y buscar la manera de afrontarla de la mejor forma posi-ble. Resumiendo, las aportaciones de los autores citados, un pensamiento potenciador es aquél que se sustenta en la verdad, es verificable (comprobable por hechos y acciones), es más un deseo que una verdad absoluta, no se plantea como necesidad, supone un reto ilusionante y está basado en la verdad objetiva.

En cambio, un pensamiento limitante, son aquellas ideas o autoverbalizaciones que perjudican el funcionamiento de la persona que lo utiliza y se caracteriza por producir una fuerte emoción desagradable de cierta duración, exagera las posibles consecuencias de tal pensamiento ("horrible", "catastrófico...), reflejan demandas absolutas u obligaciones ("tengo que", "debería"...) y/o son generalizaciones absolutistas ("todo", "nada", "esto es así"...), lo que hace además que se inhiba la acción o se funcione mal.

Las diferencias entre pensamiento potenciador y pensamiento limitante se observan de manera esquemática en la Tabla 1.

De esta manera, los pensamientos potenciadores tienen las siguientes características:

- Están formuladas en positivo (es decir, se dirigen hacia la consecución de algo).

- Se ciñen a la verdad: son consistentes con la realidad (demostrables y verificables).
- En lugar de estar planteados en términos de necesidad o absolutos, lo están en términos de deseo.

- Produce emociones moderadas y activadoras (generalmente agradables).

- Facilitan enormemente la acción: orientan hacia objetivos o metas.

- Orienta hacia retos ilusionantes.

Un aspecto importante en este sentido es diferenciar lo que serían ideas potenciadoras cuyo efecto es facilitador, de otras "falsas ideas potenciadoras" (que pueden ser incluso muy perjudiciales), que quizás aparentemente lo son pero que incumplen alguna de las características propuestas para que realmente sea una idea potenciadora (Peris-Delcampo, 2020), todo ello bien desarrollado por autores clásicos de la Psicología Cognitiva como Ellis (1980) o Beck (1987).

\section{Diez ideas potenciadoras en el deporte: una propuesta aplicada}

A continuación, presentamos una propuesta de diez pensamientos potenciadores, que cumplen las características antes citadas y que, "implantados" en el esquema cognitivo de los deportistas, favorecerán en buena medida su funcionamiento.

Estas diez creencias parten de la experiencia del presente autor en el trabajo de más de quince años en terapia cognitiva según la propuesta de Beck (1987) y Ellis (1980), por medio de la cual se identifica el pensamiento erróneo para después confrontarlo y redactar un pensamiento alternativo realista (no distorsionado, no erróneo). En base a los supuestos mencionados de la Psicología Positiva, se propone "incorporar" ideas que facilitan, en lugar de detectar el error de pensamiento para después cambiarlo. Se asume que estas diez creencias propuestas recogen el amplio abanico

Tabla 1. Diferencias fundamentales entre pensamiento potenciador vs. pensamiento limitante (adaptado de Peris-Delcampo, 2020)

Pensamiento Potenciador

- Es racional, lógico, que se sustenta en la verdad.

- Es evidente y verificable: se puede comprobar con hechos y acciones. Existen además datos objetivos que lo pueden demostrar.

- Consistente con la realidad: es verdad.

- No es absolutista: es un deseo más que un absoluto.

- No está planteado en términos de necesidad.

- Produce emociones moderadas, de baja intensidad, poda duración, en consonancia con el acontecimiento activador.

- Ayuda a conseguir metas y es facilitador de la acción.

\section{Pensamiento Limitante}

- Es irracional, se sustenta en una creencia que es ciertamente "falsa"

- Cuando se cuestiona realmente su veracidad, se comprueba que es erróneo desde el punto de vista lógico.

- Es irreal.

- Es sobregeneralizador y absolutista. Se "desvía" hacia los extremos.

- Está planteado en término de necesidad absoluta.

- Produce generalmente emociones negativas y muchas veces son tremendamente dolorosas.

- Es inhibidor de la acción: evita que se realicen acciones productivas 
de posibilidades de posibles confrontaciones de ideas erróneas, con el cambio a enfoque positivo.

La primera idea es "esfuerzo realista", se refiere a que el deportista centre todo su interés en luchar al máximo, "con los pies en el suelo", para lograr aquello que se propone, hacia una dirección y acciones determinadas. Por ejemplo, una persona, ante una dificultad, en lugar de pensar "todo me pasa a mí; debería tener más suerte", puede centrarse en lo que depende de ella teniendo presente la idea "esfuerzo realista" utilizando mensajes como "hago lo que yo sé hacer y doy el máximo de mis posibilidades".

La segunda idea es "disfrute". Entendiendo que las emociones positivas favorecen el rendimiento (Cantón y Checa, 2012), asociarlas a distintas situaciones relacionadas con la ejecución es una estrategia que mejora el funcionamiento, hace que el desgaste emocional sea menor y que, al final, provoca que las personas aprovechen mejor la actividad, además de la mejora del rendimiento. Así, por ejemplo, un deportista ante una competición de gran relevancia, en lugar de pensar "tengo que hacerlo todo perfecto" y lamentarse por ello, puede centrarse en disfrutar del proceso a través de objetivos adecuados, estimulantes que suponen un reto (idea "disfrute").

La siguiente creencia es "propia elección", en la que se entiende que la verdadera persona que sabe lo que realmente quiere y necesita es uno/a mismo/a. Los/as demás pueden opinar sobre qué sería mejor para él/ ella, pero realmente quien tiene que hacer, quien tiene que vivir las circunstancias es uno/a mismo/a. Es bueno tener en cuenta otras opiniones, obtener más información adecuada que, si se aprovecha bien, generalmente mejorará la actuación deportiva, pero eso sí, si elige cada uno/a. Cuando un deportista asume su responsabilidad por lo que le ocurre está utilizando esa creencia potenciadora.

La cuarta idea es "disputa sana", que plantea que es bueno que la persona compita al máximo, lo dé todo para lograr aquello que quiere lograr. Ahora bien, todo lo que no contribuya a ello perjudica seriamente. Si se "pelea" sanamente, centrándonos en nuestras opciones y disfrutando del proceso, nuestro rendimiento será mayor. Así, en lugar de "ir a pisar al contrario" generando emociones negativas y pensando más en cómo evitar que otros progresen y en otros pensamientos que interfieren en el propio proceso, puede tener la idea de "hago lo que quiero hacer, utilizando mis armas, centrándome en mi mismo y aceptando que otros me pueden ganar, pero sin dejar de dar mi máximo".

Cuando se habla de la quinta idea "aprender del camino", se entiende que los errores (y los aciertos) aparecerán frecuentemente. Hay gente que se perturba por ellos: por lo que podría haber hecho y se lamenta por equivocarse. En cam- bio, otros aceptan el error con naturalidad y buscan la manera de aprender de él. Esta es, sin duda, la mejor opción: aceptar las cosas como son, los errores como son y crecer cada vez más, aprendiendo de lo que ocurre. Por ejemplo, en lugar de utilizar mensajes como "tengo mala suerte", "otros tienen más enchufe que yo" o "ya no vale la pena intentarlo más, para qué"; es posible centrarnos en "aprender del camino" y pensar "cuantos más errores más oportunidades de crecer: voy a ver cómo puedo aprender de lo que ha pasado ahora".

La sexta idea potenciadora es el "auto éxito", que se refiere a que muchas veces, el éxito o el fracaso es relativo: todo depende del "color del cristal con que se mira", del punto de vista. Para algunos, lograr una medalla puede ser un éxito absoluto, mientras que, para otros, si no es de oro no lo es tanto. Cada persona elije cómo vivir su vida, cómo afronta las circunstancias y qué "listones" se impone a la hora de determinar el éxito y el fracaso. Si cada uno es responsable de su éxito y de su fracaso, ¿quién debe entonces determinar cuándo se alcanza el éxito o no? Por ejemplo, alguien puede estar demasiado pendiente de qué significa el éxito para otros y así determinar si lo ha logrado o no; o ciertamente definir qué es lo que quiere hacer y hacer todo lo posible para lograrlo. La satisfacción y rendimiento desde este planteamiento será mucho mayor en el segundo caso.

La séptima idea es "ipresente!" y entiende que hay deportistas que están más pendientes del futuro o del pasado que de lo que ocurre en este momento. $O$ bien piensan que lo que les ocurrió en el pasado marca irremediablemente lo que les ocurrirá en el futuro, como si no pudiéramos evolucionar como seres humanos, o creen que es necesario preocuparse por si en el futuro ocurren cosas catastróficas o de otro modo que nos van a hacer realmente daño. ¿Vale la pena? Realmente, sólo existe el presente: es ahí donde podemos cambiar las cosas para mejorar el futuro y/o para aprovechar lo que nos ocurrió en el pasado. Es ahí donde ciertamente podemos actuar. De esta forma, alguien puede pensar "mi pasado marca todo mi futuro y no lo puedo cambiar" o un tenista pensar en el cuadro de un torneo en lugar de centrarse en el partido actual. Es mejor pensamientos como: "voy a ver qué puedo hacer ahora para funcionar mejor en el presente y eso mejorará mi futuro" (idea "ipresente!").

La siguiente y octava idea potenciadora es "cooperación" que postula que a pesar de que sólo cada persona sabe qué es lo mejor para para sí mismo, el ser humano "es un animal social" y es bueno que se relacione con otros. Pero esta relación ha de ser de cooperación, nunca de sumisión. Aun cuando alguien "sirva" a otro, será porque él o ella lo acepte voluntariamente. Las personas funcionan mejor solas en ocasiones, pero en otras es mejor buscar la colaboración de otros de manera que todos se beneficien. Pero, eso sí, siem- 
pre con la libre elección de cada uno. Por ejemplo, alguien puede sentirse obligado a hacer lo que le marca el equipo, o sentir que sus "compañeros" de equipo son de alguna forma enemigos, o puede entender que en equipo puede lograr cosas distintas que de forma individual no podría y ser capaz de colaborar con el equipo haciendo lo que le corresponde, disfrutando del proceso y beneficiándose del trabajo común.

En la novena idea potenciadora "aceptación", se entiende que hay gente que se perturba por cómo podría ser o debería ser, encontrándose imperfecciones una y otra vez. ¿Para qué? Una cosa es buscar la mejora personal y hacer cosas para estar mejor, pero, ¿amargarse por no ser de una determinada manera? Aceptarnos tal y como somos (y buscar la mejora con naturalidad) es una buena manera de aceptar lo que nos ocurre. Cada ser humano es único y de un gran valor personal por naturaleza. Aceptémoslo. De esta forma, en lugar de pensar "si hubiera entrenado más o fuera más alto y fuerte", es mejor "tengo mis cualidades y con ellas soy lo que soy" y hacer dando el máximo.

La "verdad" (décima idea potenciadora) es la verdadera clave para vivir el momento con determinación y serenidad. Hablamos de una verdad objetiva, buscando no contentarse a sí mismo o a otros, sino buscar la manera de ver las cosas como son. Decirse mentiras sobre todo a uno mismo, genera emociones negativas y provoca acciones equivocadas. Decir mentiras a los demás hace que, en ocasiones, renunciemos a centrarnos realmente en el proceso. Ser sincero, sobre todo con uno mismo, hace que realmente encontre- mos nuestro camino y funcionemos cada vez mejor. De esta forma, en lugar de decir "seguro que ganamos hoy porque somos los mejores" (¿es realmente verdad?), es mejor analizar los puntos fuertes y débiles del rival y de los nuestros, para incorporar mensajes como "tenemos determinadas posibilidades de ganar y nos acercaremos a ellas jugando de esta forma"

\section{Estrategias para desarrollar ideas potenciadoras en el deporte}

Existen diferentes estrategias psicológicas utilizadas en la Psicología Cognitiva Conductual que pueden favorecer la implementación de las ideas potenciadoras. Detallamos algunas de ellas.

Los autorregistros se utilizan en la Psicología para tomar conciencia de un comportamiento concreto para observar la realidad objetiva (Weinberg y Gould, 1996). De esta manera es el propio individuo que anota su percepción sobre una acción, pensamiento.... determinado en base los criterios definidos y puede, por ejemplo, utilizar un autorregistro para valorar, del 0 al 10 la correcta utilización de cada idea en competición o entrenamientos con una valoración subjetiva al respecto.

Un adecuado establecimiento de objetivos facilita la acción y ayuda a regular las variables psicológicas relacionadas con el rendimiento deportivo (Morelló-Tomás et al.,

Tabla 2. Explicación de las diez ideas potenciadoras en el deporte (adaptado de Peris-Delcampo, 2020).

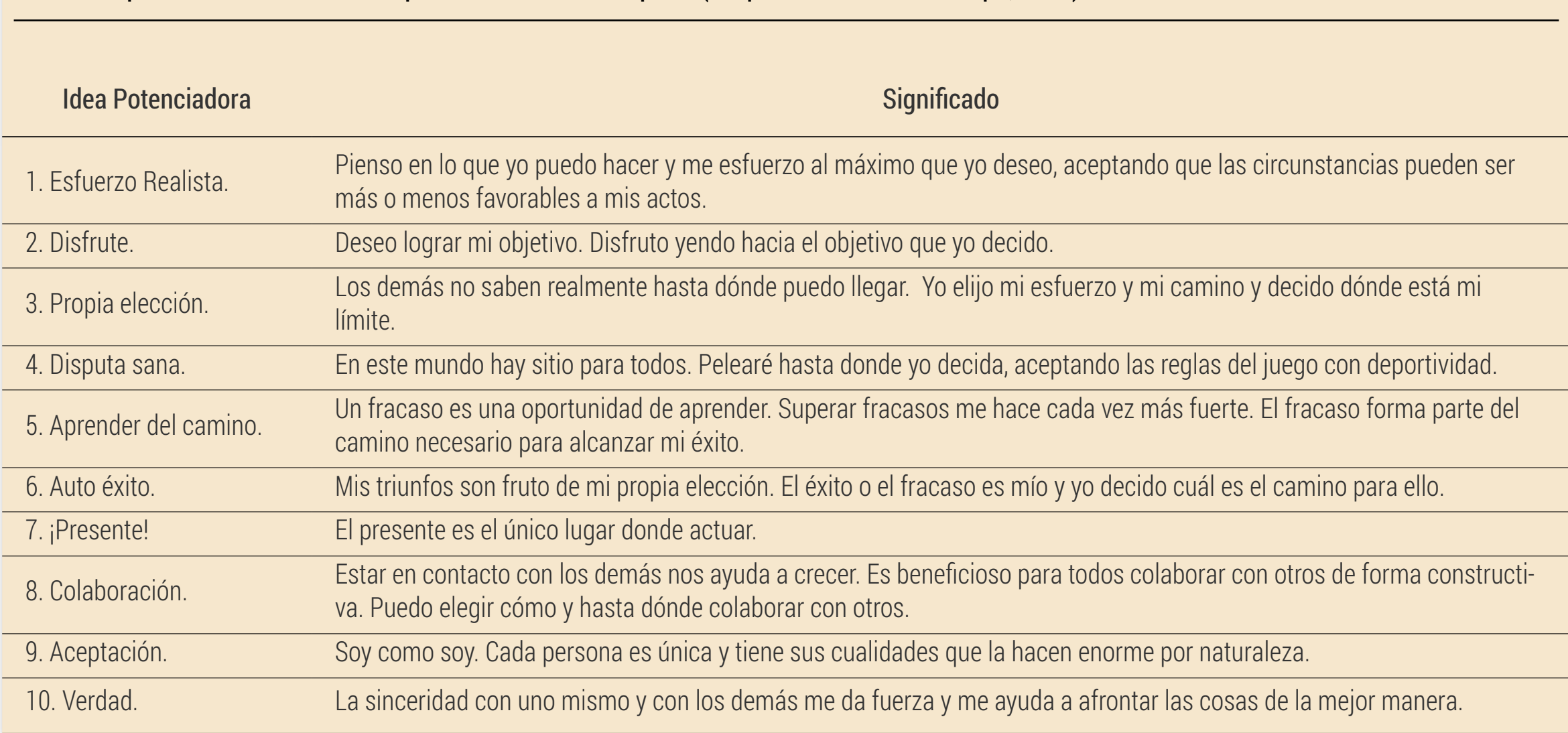


2018). Establecer los objetivos en función de las ideas potenciadoras, favorece su incorporación a la forma de funcionar tanto de los deportistas como de las demás personas implicadas (Peris-Delcampo, 2016).

La estrategia detención o parada del pensamiento (Wolpe, 1977) consiste en, tras detectar un pensamiento limitante en medio de (en este caso) una competición o un entrenamiento, se elige una palabra o una acción para "cortar" ese pensamiento automático limitante y después introducir frases o pensamientos (ideas potenciadoras) que faciliten la acción. Esta estrategia hay que entrenarla suficientemente para automatizarla y utilizarla con eficiencia sobre todo en los momentos de mayor exigencia en competiciones y entrenamientos.

La comunicación de los entrenadores y demás miembros del staff con sus deportistas es un elemento clave para manejar aspectos psicológicos (Vives-Ribó, 2011; Vives-Ribó y Rabassa, 2020). Utilizan mensajes tanto en sus charlas, reuniones con deportistas de manera individual, grupos de Whatsapp, frases escritas y colgadas en el vestuario, ruedas de prensa... por lo que es una buena oportunidad para preparar esos mensajes que incluyan ideas potenciadoras.

Las palabras clave o anclajes (Weinberg y Gould, 1996), se utilizan en Psicología del Deporte para asociar un determinado estado, emoción, acción... a una palabra o expresión, de manera que al aparecer el anclaje se reproduce aquello que se ha entrenado por asociación. La utilización de palabras clave se pueden aprovechar para incorporar ideas potenciadoras a la palabra o expresión que supone el anclaje.

Las autoinstrucciones (Latinjak et al., 2018; Meinchenbaum, 1977) son mensajes preparados que se dice una persona que le orienta a la acción. Resulta evidente la importancia de incorporar ideas potenciadoras en las autoinstrucciones, de manera que cuando un deportista u otro agente del deporte se dice algo a sí mismo en forma de autoinstrucciones, se está mandando mensajes relacionados con alguna idea potenciadora.

Por medio de la reestructuración cognitiva (Garcia y Rajo, 2020) se confrontan las ideas automáticas distorsionadas o irracionales (limitantes) para cambiar el funcionamiento cognitivo por medio de preguntas adecuadas y otros cuestionamientos. Resulta obvio entender que por medio de esta técnica psicológica se "sustituyen" las ideas limitantes por otras potenciadoras.

En los debates colectivos (Peris-Delcampo, 2016; Weinberg y Gould, 1996) un miembro del staff (también en ciertos casos podría ser un profesional externo o incluso otro deportista, como el capitán) conduce una sesión en grupo en la que los deportistas toman una decisión respecto a ciertos aspectos que interesa implementar, hasta que se lleguen a unas conclusiones que "sean de todos" y por tanto favorezca la implicación. Esas conclusiones pueden llevar implícitas las ideas potenciadoras propuestas.

El coaching, entendido como una estrategia por medio de la cual se genera un entorno facilitador tomando como base los propios recursos de la persona que se beneficia del coaching, en busca de la consecución de unos determinados objetivos (Garcia-Naveira, 2016), encaja perfectamente en la combinación de esta estrategia psicológica con la incorporación de ideas potenciadoras, ya que puede tener como base el conocimiento y aplicación de las mismas durante el proceso de coaching (Peris-Delcampo,2016).

\section{Discusión}

La presente propuesta se fundamenta principalmente en el enfoque cognitivo conductual, que integra la Psicología Cognitiva y Psicología Positiva. En el mismo los procesos cognitivos, pensamiento, ideas, imágenes... determinan nuestras emociones y conductas. A pesar de ello, se debe señalar la necesidad de mantener un principio de unidad afectivo y cognitivo. Las emociones dan lugar también a pensamientos, ideas, imágenes y conductas (e,g., me siento "triste", pienso que "no soy capaz" y "no disputo un balón o lo hago sin la suficiente fuerza").

Además de la definición de los tipos de pensamientos potenciadores y limitantes, se debería de considerar igualmente en futuros trabajos los pensamientos irrelevantes o neutros, que, no siendo emocionalmente negativos desde el punto de vista afectivo, pueden ocasionar que se perturben los procesos cognitivos, impidiendo que esos pensamientos potenciadores estén presentes en el momento del rendimiento (e.g., pensar en los espectadores y lo que hacen, en lugar de centrarse en lo que depende del propio deportista y en lo relevante, en el "aquí y ahora" para pasar a la acción).

Por otro lado, la lista de pensamientos potenciadores es muy amplia y variada, lo que podría llevar al sobre análisis en algunos casos. Éste, a su vez, puede paralizar la acción del deportista. Tal vez, dentro de la alianza profesional deportista-psicólogo, se podrían seleccionar las creencias más significativas para su implementación, en función de cada caso y circunstancias.

Desde una perspectiva científica-profesional, los psicólogos del deporte aplicados precisan de herramientas fundamentadas y útiles para realizar su trabajo con eficiencia, adaptándose a las necesidades que se les demanda y en muchas ocasiones con escaso margen de tiempo. Sería útil validar el empleo de esta intervención a partir de cada uno de los pensamientos potenciadores y estrategia de implemen- 
tación y que brinde información que valide esta propuesta, como es el caso del trabajo de Peris-Delcampo (2019) al aplicar las diez ideas potenciadoras en una intervención online con un jugador de fútbol.

Para terminar, destacar que el psicólogo/a requiere de una formación especializada y experiencia profesional en Psicología del Deporte para realizar intervenciones eficaces y adaptadas al contexto (Cantón, 2016) y en este caso además, formación en trabajo con creencias y pensamientos potenciadores y limitantes (Smith y Kosslyn, 2008).

\section{Referencias}

Alarcón, F., Ureña, N. y Cárdenas, D. (2017). La fatiga mental deteriora el rendimiento en el tiro libre en baloncesto. Revista de Psicología del Deporte, 26(1), 33-36.

Alesi, M., Gómez-López, M. y Bianco, A. (2019). Diferenciación motora y habilidades cognitivas en la edad preescolar. Cuadernos de Psicología del Deporte, 19(1), 50-59.

Beck, A.T. (1987). Cognitive Therapy of Depression. The Guildford Press.

Beck, J. S. (1995). Cognitive Therapy: Basics and Beyonds. The Guildford Press.

Cantón, E. (2016). La especialidad profesional en Psicología del Deporte. Revista de Psicología aplicada al Deporte y al Ejercicio Físico, 1(1), Artículo e2. https://doi.org/10.5093/rpadef2016a2

Cantón, E. y Checa, I. (2012). Los estados emocionales y su relación con las atribuciones y las expectativas de autoeficacia en el deporte. Revista de Psicología del Deporte, 21(1), 171-176.

Camacho, J., Ochoa, N. y Rincón, N. (2019). Revisión teórica de la planificación tradicional y contemporánea en el entrenamiento deportivo. Revista Digital: Actividad Física y Deporte, 5(2), 171181. https://doi.org/10.31910/rdafd.v5.n2.2019.1265

Del Valle, S. y De la Vega, R. (2008). La regulación de la representación en los modelos emergentes en el Deporte. Perspectiva cognitiva. Retos. Nuevas tendencias en Educación Física, Deporte y Recreación, 13, 19-27.

Ellis, A. (1980). Razón y Emoción en Psicoterapia. Desclée de Brouwer.

Eysenck, M. W. (1990). Cognitive Psychology: An International Review. John Wiley \& Sons, Ltd.

Fernández-Campoy, J. M., Aguilar-Parra, J. M. y Padilla, D. (2016). La actividad física y deportiva como medio para la reducción de los niveles de deterioro cognitivo en las personas mayores. International Journal of Developmental and Educational Psychology, 1(2), 465-473. https://doi.org/10.17060/ijodaep.2016. n2.v1.584

Festinger, L. (1957). A theory of cognitive dissonance. Stanford University Press.

García-Jarillo, M., De Francisco, C., Ortín, F. J. y Garcés de Los Fayos, E. J. (2020). Sintomatología del síndrome de burnout en deportistas: un estudio con metodología Delphi. Cuadernos de Psicología del Deporte, 20(3), 15-25. https://revistas.um.es/cpd/ article/view/367531
García-Naveira, A. (2016). Percepción del bienestar y de la salud psicológica, y la eficacia de un programa de intervención en coaching en deportistas de rendimiento. Revista Iberoamericana de Psicología del Ejercicio y el Deporte, 17(2), 211-219.

García-Naveira, A. (2018). Pasado, presente y futuro del psicólogo del deporte en el fútbol español. Revista de Psicología aplicada al Deporte y al Ejercicio Físico, 3(1), Artículo e2. https://doi. org/10.5093/rpadef2018a8

García, M. D. V. y Rajo, M. M. (2020). Psicología cognitiva. Ediciones Pirámide.

Hayes, S. C., Strosahl, K. D. y Wilson, K. G. (2015). Acceptance and Commitment Therapy: The Process and Practice of Mindful Change (Second revised edition). The Guilford Press.

Latinjak, A. T., Ramis, Y., Hatzigeorgiadis, A. y Torregrosa, M. (2018). Autohabla y deporte: Una revisión interpretativa. Revista de Psicología del Deporte, 27(2), 75-86.

Lazarus, R. S. y Folkman, S. (1986). Estrés y Procesos Cognitivos. Martínez Roca.

Meichenbaum, D. H. (1977). Cognitive behavior modification: An integrative approach. Plenum Press.

Morelló-Tomás, E., Vert-Boyer, B. y Navarro, S. (2018). Establecimiento de objetivos en el currículum formativo de los futbolistas. Revista de Psicología aplicada al Deporte y al Ejercicio Físico, 3(1), Artículo e3. https://doi.org/10.5093/rpadef2018a7

Nieto, M. M., Chinchilla, J. L. y Castillo, A. (2020). Estudio de los procesos cognitivos en bailarines semi-profesionales. Retos: nuevas tendencias en educación física, deporte y recreación, 37(37), 493-497. https://doi.org/10.47197/retos.v37i37.70936

Palmi, J. y Solé, S. (2016). Intervenciones basadas en mindfulness (atención plena) en psicología del deporte. Revista de Psicología del Deporte, 25(1), 147-155.

Peris-Delcampo, D. (2016). Nociones básicas de psicología del deporte y coaching para gestores de empresas deportivas. Círculo Rojo.

Peris-Delcampo, D. (2019). Intervención psicológica a distancia con un futbolista profesional: estudio de caso. Revista de Psicología Aplicada al Deporte y el Ejercicio Físico, 4(2), e15. https:// doi.org/10.5093/rpadef2019a14

Peris-Delcampo, D. (2020). Ideas potenciadoras vs ideas limitantes. Máster en Coaching y Liderazgo de la Universidad de Valencia. Fundación Universidad Empresa ADEIT.

Peris-Delcampo, D. y Cantón, E. (2018). El perfil profesional del psicólogo especialista en psicología del deporte en fútbol. Revista de Psicología Aplicada al Deporte y el Ejercicio Físico, 3(1), Artículo e9. https://doi.org/10.5093/rpadef2018a6

Reigal, R. E., Borrego, J. L., Juárez, R. y Hernández-Mendo, A. (2016). Práctica física y funcionamiento cognitivo en una muestra adolescente. Revista Iberoamericana de psicología del ejercicio y el deporte, 17(2), 201-209.

Segan, Z.V., Williams, M.G. y Teasdale, J. D. (2015). Terapia Cognitiva basada en el Mildfuldness para la Depresión. Kairós.

Smith, E. y Kosslyn, S. (2008). Procesos cognitivos: modelos y bases neurales. Pearson Educación. https://doi.org/10.1007/s10339007-0200-0

The APA 1998 Annual Report (1999). American Psychologist, 54(8), 537-568. https://doi.org/10.1037/0003-066X.54.8.537 
Vives-Ribó, J. (2011). Entrenando al entrenador. Ideas y trucos para una comunicación constructiva y eficaz. Bubok.

Vives-Ribó, J. y Rabassa, N. (2020). Intervención sobre la comunicación del entrenador para aumentar la confianza de los deportistas. Revista de Psicología Aplicada al Deporte y el Ejercicio Físico, 5(1), Artículo e6. https://doi.org/10.5093/rpadef2020a1

Vygotsky, L. S. (1979). El desarrollo de los procesos psicológicos superiores. Crítica.
Wright, J. H. (1988). Cognitive therapy of depression. En A. J. Frances y R. E. Hales (Eds.), The American Psychiatric Press review of psychiatry (vol 7). American Psychiatric Press.

Weinberg, R. S. y Gould, D. (1996). Fundamentos de psicología del deporte y el ejercicio físico. Ariel

Wolpe, J. (1977). La práctica de la terapia de conducta. Trillas. 